\title{
Effect of Combined High Pressure and Thermal Treatment on Myofibrillar Proteins Solubilization of Beef Muscle
}

\section{Hanjun Ma ${ }^{1, *}$, Guanghong Zhou ${ }^{2}$, David A. Ledward ${ }^{3}$, Xiaoling Yu ${ }^{1}$ and Runshu Pan ${ }^{1}$}

1 School of Food Science, Henan Institute of Science and Technology, Xinxiang 453003, China; E-Mails: yuxiaoling@163.com (X.Y.); prsh@hist.edu.cn (R.P.)

2 Key Laboratory of Food Processing and Quality Control, College of Food Science and Technology, Nanjing Agricultural University, Nanjing 210095, China; E-Mail: ghzhou@ @jau.edu.cn

3 Department of Food Biosciences, University of Reading, Whiteknights, Reading RG66AP, UK; E-Mail: david.ledward@ nottingham.ac.uk

* Author to whom correspondence should be addressed; E-Mail: xxhjma @126.com; Tel.: +86-373-3040979; Fax: +86-373-3040709.

Received: 7 March 2011; in revised form: 29 March 2011 / Accepted: 29 April 2011 / Published: 11 May 2011

\begin{abstract}
The effects of high pressure (to $600 \mathrm{MPa}$ ) at different temperatures (20 to $60{ }^{\circ} \mathrm{C}$ ) for $20 \mathrm{~min}$ on protein solubilization and electrophoretic pattern in beef post-rigor longissimus dorsi muscle were studied. The results showed that protein solubilization increased with increasing temperature, especially from $40{ }^{\circ} \mathrm{C}$ to $60{ }^{\circ} \mathrm{C}$. A regular trend of protein solubilization was found when isolated myofibrils were subjected to high pressure at different temperatures, an increase was observed with increasing pressure up to about $400 \mathrm{MPa}$, solubility then decreasing to $600 \mathrm{MPa}$. Electrophoretic profiles showed that myosin light chains and actin thin filaments were sensitive to pressure, and were released from myofibrils subjected to $100 \mathrm{MPa}$ and higher pressures at the different temperatures.
\end{abstract}

Keywords: high pressure; keyword; myofibril; protein solubilization; electrophoresis

\section{Introduction}

High pressure processing is becoming increasingly used by the meat industry, as it can extend shelf life and improve the eating quality and functional properties of meat and meat products [1-3]. High pressure treatment can tenderize meat when applied pre-rigor, but it does not necessarily have such an 
effect on post-rigor meat at room temperature $\left(20^{\circ} \mathrm{C}\right)$ [4]. However, it is difficult for the industry to treat pre-rigor meat with high pressure [5]. Spores at ambient temperature can resist pressures up to $1000 \mathrm{MPa}$, but lower pressures $(250 \mathrm{MPa})$ associated with mild temperatures $\left(40{ }^{\circ} \mathrm{C}\right)$ can inactivate spores in a two stage process, pressure first inducing germination and then inactivating the baro-sensitive germinated spores [6], showing the benefits of combining high pressure technology with heat treatment. Therefore, high pressure technology can be applied in combination with heat treatment.

Myofibrillar proteins have a significant relationship with meat functional properties, therefore it is important to understand the changes that happen to the myofibrillar proteins. Many previous investigations have shown that as a consequence of depolymerization, pressure induces increased solubilization of myofibrillar proteins. Macfarlane et al. reported that when ovine meat is pressurized at $150 \mathrm{MPa}$, a marked increase in the yield of solubilized myofibrillar proteins occurs, but the effects were dependent on $\mathrm{pH}$, temperature, and salt type and concentration [7,8]. Similar observations were observed by Suzuki et al. in rabbit meat [9]. These authors found that proteins from the thin filament such as actin, tropomyosin, troponin $\mathrm{C}$ as well as M-protein were solubilized at $100 \mathrm{MPa}$, whereas solubilization of myosin heavy chains required higher pressures (300 MPa). McArthur and Wilding [10] observed no solubilization of myosin heavy chains, even at $500 \mathrm{MPa}$, although myosin was shown to be partly denatured by differential scanning calorimetry.

The changes in myofibrillar proteins subjected to high pressures have been studied, but these studies were limited to ambient temperature. In the present study the effects of combined heat and pressure treatments on isolated myofibril solubility and protein electrophoretic pattern were investigated. The objective was to further understand the relative effects of heat and pressure treatments on the myofibrillar proteins of beef muscle.

\section{Results and Discussion}

\subsection{Effect of Pressure and Heat on the Solubilization of the Proteins}

The effects of high pressure and temperature on the solubilization of myofibrillar proteins are presented in Figure 1.

On heat treatment at ambient pressure, the expected increase in the solubility of myofibrillar proteins with increasing temperature $(\mathrm{P}<0.05)$, especially from $40{ }^{\circ} \mathrm{C}$ to $60{ }^{\circ} \mathrm{C}$, was observed, where the concentration of soluble myofibrillar proteins increased from $0.273 \mathrm{mg} / \mathrm{mL}$ to $0.747 \mathrm{mg} / \mathrm{mL}$.

At $20{ }^{\circ} \mathrm{C}$, increasing pressure led to an increase in solubility of myofibrillar proteins, up to $400 \mathrm{MPa}$ $(1.403 \mathrm{mg} / \mathrm{mL})$, the highest concentration for all treatments, after which a significant decrease with a further increase in pressure was observed. The pressure induced solubilization of beef myofibrillar proteins is similar to the results obtained for chicken [11]. Jung, Lamballerie-Anton and Ghoul also found increases in soluble protein at $300 \mathrm{MPa}$ compared to the control and treatment at $100 \mathrm{MPa}$, but there was no significant change when pressure was increased from 300 to $600 \mathrm{MPa}$ [12].

In comparison with the results obtained at $20^{\circ} \mathrm{C}$ similar trends of protein solubilization were found when isolated myofibrils were subjected to pressure at $40{ }^{\circ} \mathrm{C}$ and $60{ }^{\circ} \mathrm{C}$, an increase being observed with the increasing pressure up to $400 \mathrm{MPa}$, with a subsequent decrease at $600 \mathrm{MPa}$. Although similar trends of protein solubilization were found for pressure treatment at all temperatures, the extent and 
variability of the concentrations of soluble myofibrillar proteins differed at related pressures, which may be due to interactions between pressure and temperature.

Figure 1. Changes in the concentration of myofibrillar protein in the supernatants obtained on centrifugation of the myofribillar extract after pressure treatment at (a) $20{ }^{\circ} \mathrm{C}$, (b) $40{ }^{\circ} \mathrm{C}$, and (c) $60{ }^{\circ} \mathrm{C}$. $0.1 \mathrm{MPa}$ is ambient pressure (control); a-e: means with different letters are significantly different $(\mathrm{P}<0.05)$ between pressure treatments at a given processing temperature.

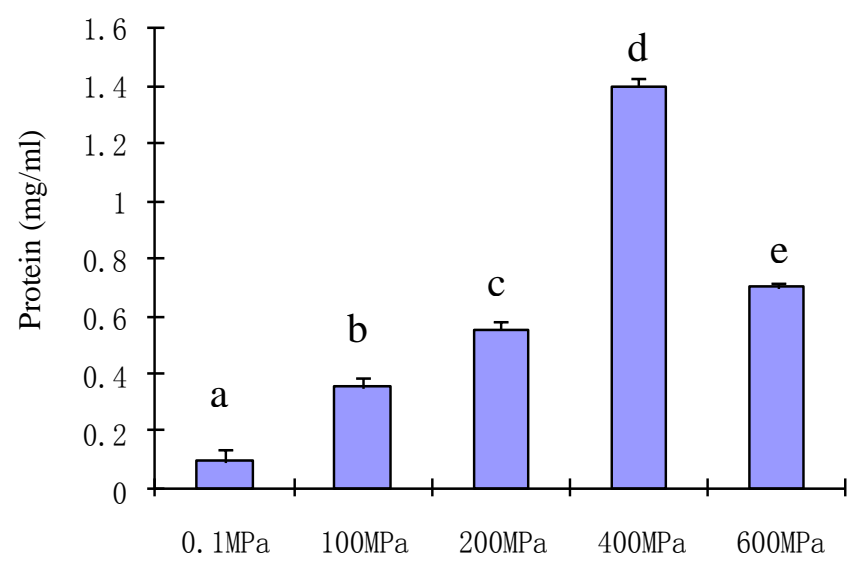

(a)

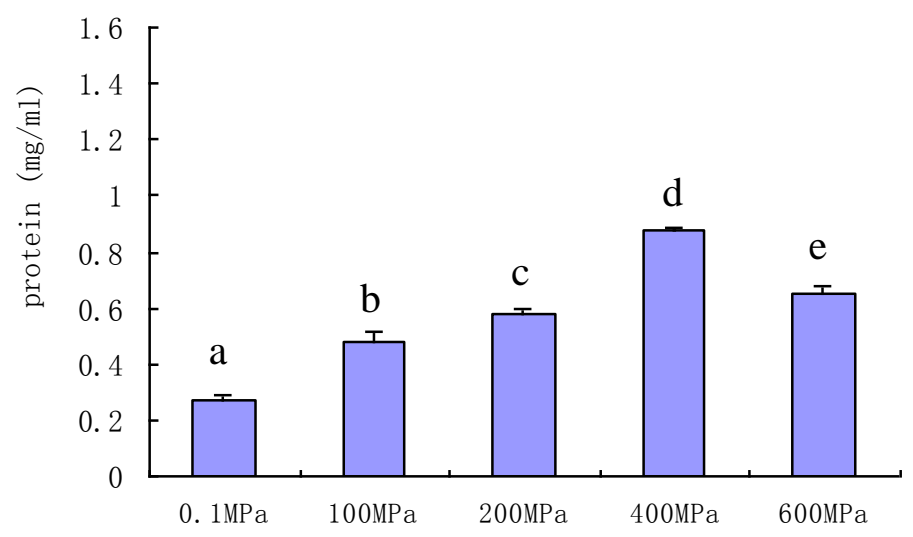

(b)

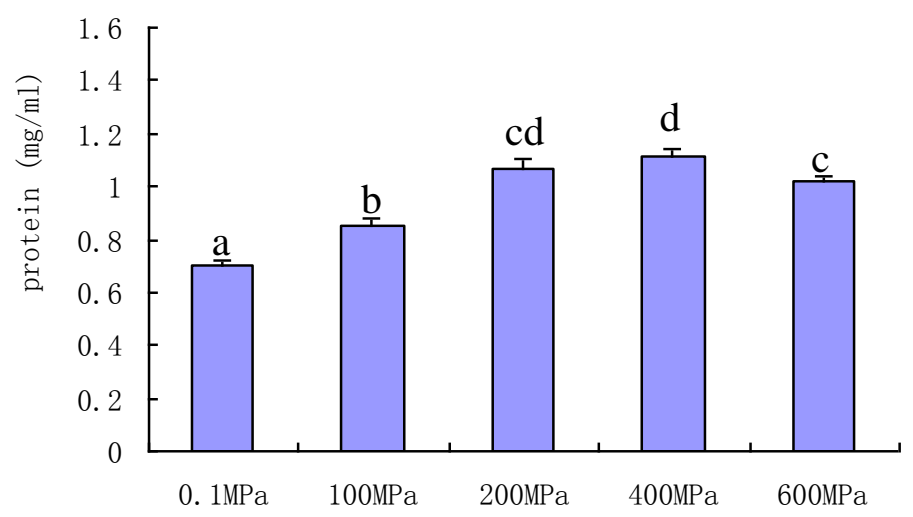

(c) 
2.2. Effect of Combined Pressure and Thermal Treatment on the Myofibrillar Proteins by SDS-PAGE Analysis

SDS-PAGE profiles from supernatants and precipitates of the myofibrils after pressure treatment at $20^{\circ} \mathrm{C}$ are shown in Figure 2. From Figure 2 and the relative intensity of the bands (data not shown), it was found that proteins molecular weights over $41 \mathrm{kDa}$ decreased in the supernatant, while proteins in the molecular weight range $35-16 \mathrm{kDa}$ increased in both the supernatant and precipitate when samples were subjected to pressures over $100 \mathrm{MPa}$, due to depolymerization of the myofibrillar proteins treated at higher pressures.

Figure 2. SDS-PAGE profiles from supernatants (A) and precipitates (B) of myofibrils after pressure treatment at $20{ }^{\circ} \mathrm{C}$. M: myofibril; S: molecular weight standards; $1,2,3,4$ and 5 represent control samples and samples after treatment at 100, 200, 400, $600 \mathrm{MPa}$, respectively. MHC: myosin heavy chain; $\alpha$ : $\alpha$-actinin; A: actin; Tn-T: troponin T; Tm: tropomyosin; Tn-I: troponin I; Tn-C: troponin C; LC1, 2, 3 represent myosin light chains 1 , 2,3 , respectively.

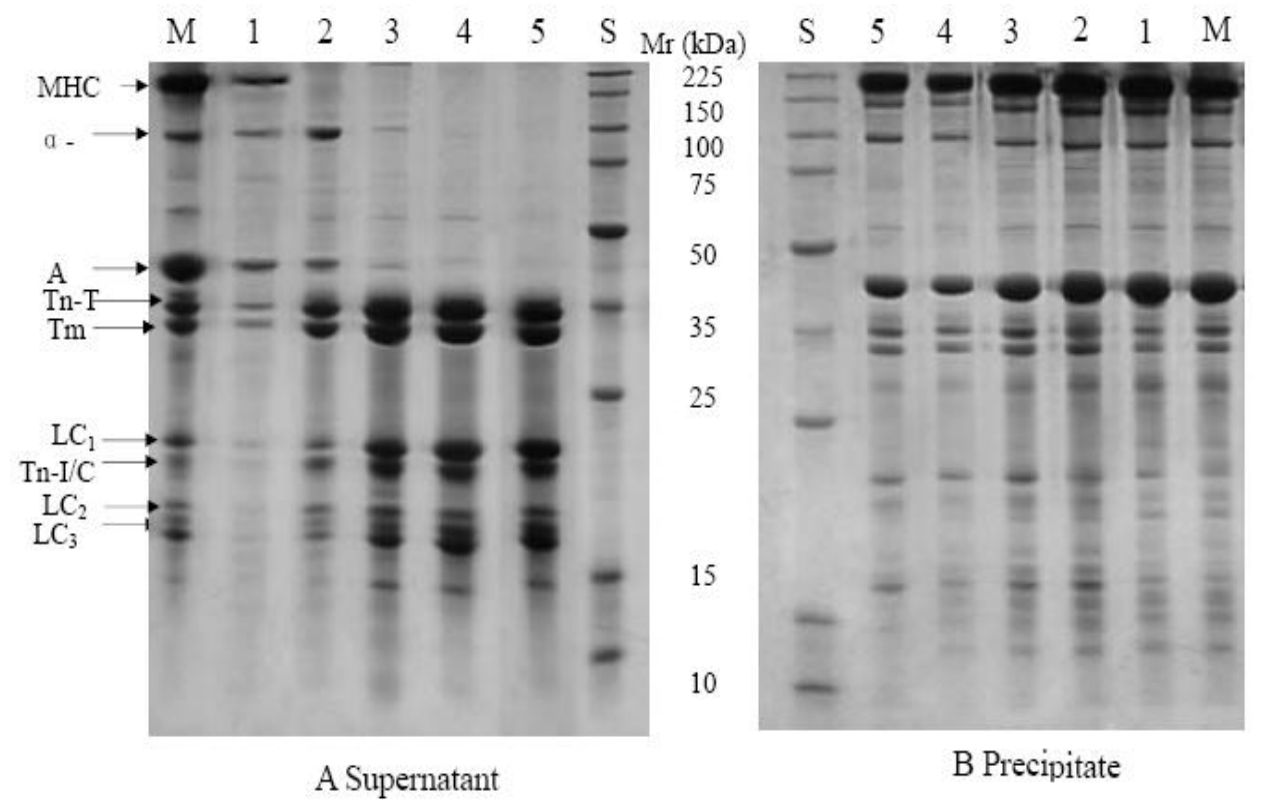

Myosin heavy chain was observed in the supernatant from the control but was absent in the pressure treated samples. This is in agreement with Yamamoto et al. who found that the band of the myosin heavy chain was not observed in samples pressurized at $300 \mathrm{MPa}$ for 10 to $30 \mathrm{~min}$ [11]. This was attributed to the fact that the myosin heavy chain is not stable to pressurization and denatures to appear in the precipitate. The solubility of the myosin light chain increased with increasing pressure, as demonstrated by changes in the density of this band in the supernatant profiles.

$\alpha$-Actinin is a component of the $\mathrm{Z}$ line of the myofibril. After treatment at $100 \mathrm{MPa}$, the density of this band in the supernatant was greater than in the control, but it disappeared gradually with increasing pressure, indicating that the solubility of $\alpha$-actinin increased when subjected to $100 \mathrm{MPa}$ at room temperature but decreased thereafter. Actin was observed in the supernatant of samples pressurized at $100 \mathrm{MPa}$ for $20 \mathrm{~min}$, but disappeared at pressures above $200 \mathrm{MPa}$. This result differs 
from Yamamoto et al. who observed actin in the supernatants after treatment at 300 and $400 \mathrm{MPa}$ that was unchanged with increasing pressure [11]. Troponin T, I/C and Tropomyosin, which are major components of thin filaments, were solubilized by pressure treatment, as the densities of these protein bands increased in the supernatants and decreased in the precipitates with increasing pressure. Thin filaments are sensitive to pressure and depolymerize into G-actin [13]. June et al. also reported that the solubility of Troponin T, Tropomyosin and myosin light chains increased after pressure treatment [12].

In the samples pressure treated at $40{ }^{\circ} \mathrm{C}$ and $60{ }^{\circ} \mathrm{C}$, similar protein solubility changes were found (Figure 3 and Figure 4). New banding patterns were observed. Lower molecular weight bands (below $35 \mathrm{KDa}$ ) increased with the pressure up to 200 or $400 \mathrm{MPa}$ in the supernatants, but there were no significant changes in the precipitates. These results are similar to those of Sikes et al. who found that when the myofibrillar proteins of beef neck were treated at $200 \mathrm{MPa}$ and $60{ }^{\circ} \mathrm{C}$ for $20 \mathrm{~min}$ a new type of structure between myosin and actin was formed and the myofibrillar proteins degraded to smaller molecules [14]. In the present study the band with the molecular weight of about $18 \mathrm{KDa}$ (LC2) disappeared in the samples pressure treated at $40{ }^{\circ} \mathrm{C}$ and $60{ }^{\circ} \mathrm{C}$, presumably due to the interactive effect of pressure and temperature treatment.

Figure 3. SDS-PAGE profiles from supernatants (A) and precipitates (B) of myofibrils after pressure treatment at $40{ }^{\circ} \mathrm{C}$. M: myofibril; S: molecular weight standards; $1,2,3,4$ and 5 represent control samples and samples after treatment at 100, 200, 400, $600 \mathrm{MPa}$, respectively. MHC: myosin heavy chain; $\alpha$ : $\alpha$-actinin; A: actin; Tn-T: troponin T; Tm: tropomyosin; Tn-I: troponin I; Tn-C:troponin C; LC1, 3 represent myosin light chains 1 and 3 , respectively.

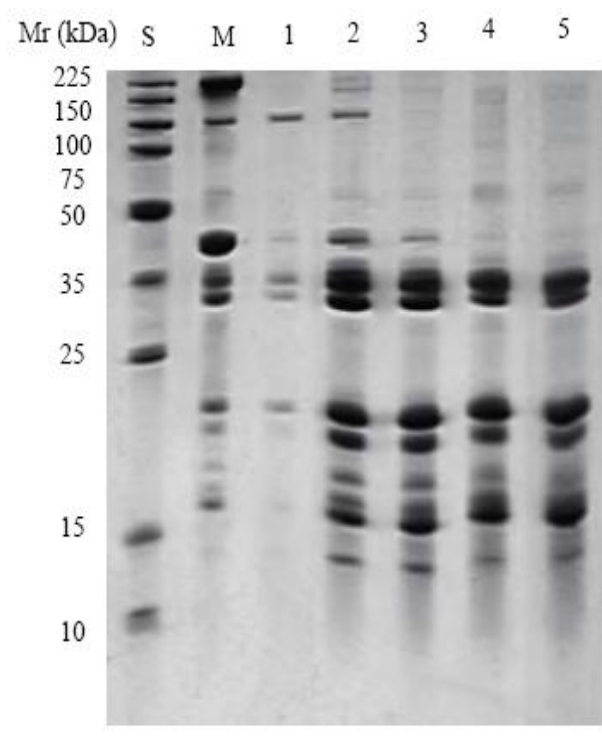

A Supermatant

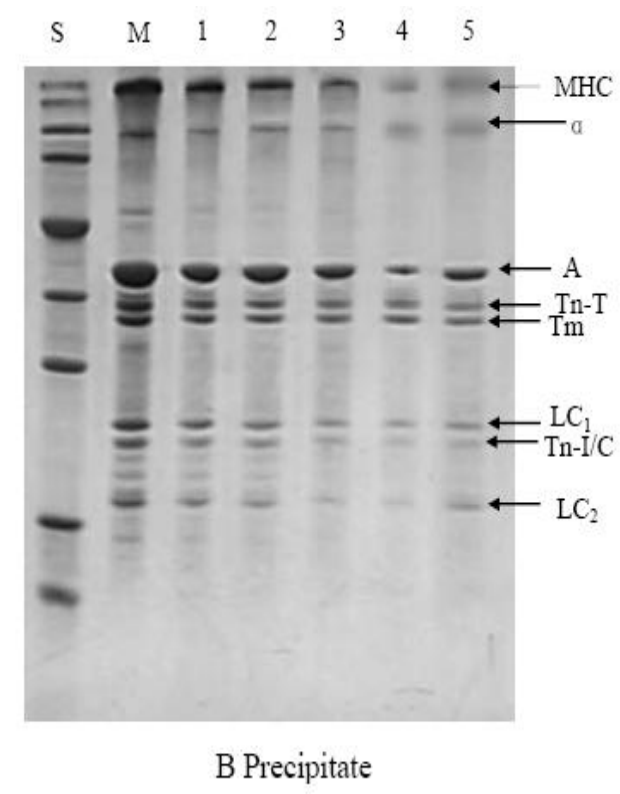


Figure 4. SDS-PAGE profiles from the supernatants (A) and precipitates $(\mathbf{B})$ of myofibril after pressure treatment at $60{ }^{\circ} \mathrm{C}$. S: molecular weight standards; $1,2,3,4$ and 5 represent control samples and samples after treatment at 100, 200, 400, 600MPa. MHC: myosin heavy chain; $\alpha$ : $\alpha$-actinin; A: actin; Tn-T: troponin T; Tm: tropomyosin; Tn-I: troponin I; Tn-C:troponin C; LC1, 3 represent myosin light chains 1 and 3, respectively.
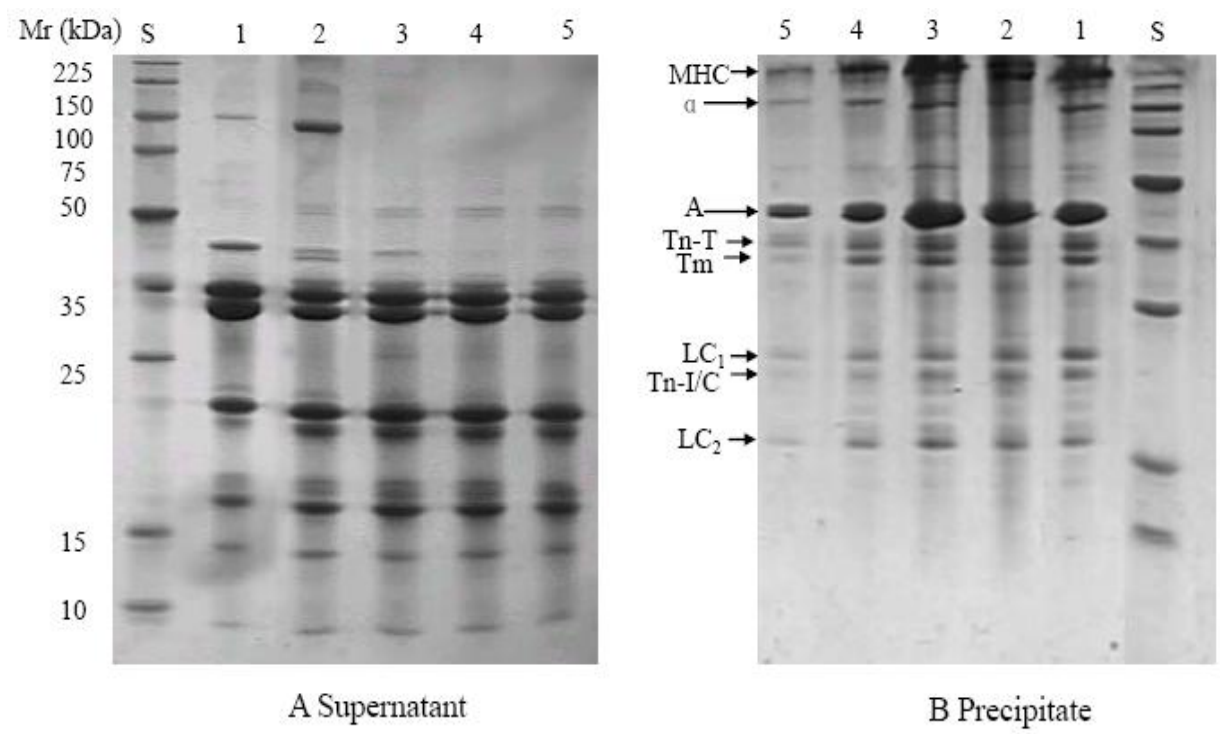

\section{Experimental Section}

\subsection{Sample Preparation}

The beef Longissimus dorsi was obtained from a supermarket in Nanjing, China. The meat was from two 20-24 month old Luxi $\times$ Limousin crossbreeds, the weight of each side of the carcass was about $130 \mathrm{~kg}$ and had been kept at $4{ }^{\circ} \mathrm{C}$ for 3 days following slaughter. The beef sample was trimmed of all visible fat and cut into approximately $3 \times 3 \times 6 \mathrm{~cm}$ pieces with the fibers parallel to the longest axis, and packed in Multivac bags (Bosley International, London, UK), which were maintained at $4{ }^{\circ} \mathrm{C}$ for over $48 \mathrm{~h}$ until required [15].

\subsection{Myofibrillar Extraction}

Myofibrils were extracted using the method of Busch et al. [16]. Minced beef was homogenized for $20 \mathrm{~s}$ in a Waring blender (Stomacher 400, Paris, France) with six volumes of extraction buffer (20 mM Tris-HCl, pH 7.6, $5 \mathrm{mM}$ EDTA). After centifugation at $1000 \mathrm{~g}$ for $10 \mathrm{~min}$ at $4{ }^{\circ} \mathrm{C}$, the pellets were resuspended in the extraction buffer and the operation repeated five times. After the last centrifugation, the pellets were resuspended in five volumes of extraction buffer and homogenized in a Waring blender for $25 \mathrm{~s}$. In order to remove the connective tissue, the homogenate was filtered through a 20 mesh nylon net (Shanghai Hailiang Filter Cloth CO., Ltd., Shanghai, China), centrifuged at $1000 \mathrm{~g}$ for $10 \mathrm{~min}$ and washed with the buffer. The pellets were resuspended in $100 \mathrm{mM} \mathrm{KCl}$, centrifuged under the same conditions and finally homogenized in $100 \mathrm{mM} \mathrm{KCl}$. The concentration of the solution was adjusted to $6 \mathrm{mg} / \mathrm{mL}$. Samples of $10 \mathrm{~mL}$ were sealed in Multivac bags (Bosley International, London, UK) for treatment. 


\subsection{High Pressure and Heat Treatment}

Myofibrils were treated at 100 to $600 \mathrm{MPa}$ at room temperature, 40 and $60{ }^{\circ} \mathrm{C}$ for $20 \mathrm{~min}$ in the high pressure rig (Kefa New Technology Food Machine, Ltd., Baotou, China). The pressure unit comprised a $3 \mathrm{~L}$ cylindrical pressure chamber fitted with a thermoregulated system. Room temperature was the control, $20{ }^{\circ} \mathrm{C}$. Some myofibrillar samples were heated, in water baths at 40 and $60{ }^{\circ} \mathrm{C}$ for $20 \mathrm{~min}$, as controls. All experiments were carried out in triplicate.

\subsection{Assay of Protein Solubility}

After pressure treatment, samples of myofibrils were centrifuged for $20 \mathrm{~min}$ at $14,000 \mathrm{~g}$ and $4{ }^{\circ} \mathrm{C}$, supernatants and precipitates from each sample were collected. The protein concentration of the supernatant was determined by BCA kit (Pierce Biotechnology, Int., Rockford, IL, USA).

\subsection{Electrophoretic Analysis}

The SDS-PAGE analysis was conducted using a $12.5 \%$ acrylamide gradient separating gel and $4 \%$ acrylamide stacking gel, as in Laemmli (1970) [16]. Samples of supernatant and precipitate (mixed with 8 volumes of buffer) were mixed with SDS-PAGE sample buffer (4\% SDS, 20\% glycerol, $0.125 \mathrm{M}$ Tris- $\mathrm{HCl}, 10 \% \beta$-mercaptoethanol $[\mathrm{pH}$ 6.87]) in a $1: 1(\mathrm{v} / \mathrm{v})$ ratio were heated in boiling water for $3 \mathrm{~min}$. Aliquots of $20 \mu \mathrm{g}$ of protein per lane were loaded onto the acrylamide gel. Electrophoresis was first run at $80 \mathrm{~V}$ for about $30 \mathrm{~min}$, and then at $120 \mathrm{~V}$ for $3 \mathrm{~h}$. Gel was stained in Coomassie brilliant blue R-250 (0.1\% Coomassie brilliant blue R-250, 45\% methanol, $10 \%$ acetic acid) for $2 \mathrm{~h}$. Destaining was in $10 \%$ methanol, $10 \%$ acetic acid for $12 \mathrm{~h}$.

\subsection{Statistical Analysis}

Data were analyzed by a two way analysis of variance. A confidence level of 5\% was used to compare means $(\mathrm{P}<0.05)$. When significance was detected between samples, the mean values were compared using Fisher's least significant difference (LSD) procedure.

\section{Conclusions}

The solubility of myofibrillar proteins varied with pressure and temperature, but the highest solubility was induced by treatment at room temperature and $400 \mathrm{MPa}$. Myosin light chains and actin thin filaments were sensitive to pressure, and were released from myofibrils subjected to $100 \mathrm{MPa}$ and higher pressures at the different temperatures tested.

\section{Acknowledgements}

The authors are thankful to Haizhen $\mathrm{Zu}$ in Nanjing Agricultural University for her technical assistance of SDS-PAGE analysis. This study was supported by National Natural Science Foundation of China (31040062). 


\section{References}

1. Hugas, M.; Garriga, M. Monfort, J.M. New mild technologies in meat processing: High pressure as a model technology. Meat Sci. 2002, 62, 359-371.

2. Torres, J.A.; Velazquez, G. Commercial opportunities and research challenges in the high pressure processing of foods. J. Food Engineer. 2005, 67, 95-112.

3. Marcos, B.; Kerry, J.P.; Mullen, A.M. High pressure induced changes on sarcoplasmic protein fraction and quality indicators. Meat Sci. 2010, 85, 115-120.

4. Ma, H.J.; Ledward, D.A. High pressure/thermal treatment effects on the texture of beef muscle. Meat Sci. 2004, 68, 347-355.

5. Cheftel, J.C.; Culioli, J. Effects of high pressure on meat: A review. Meat Sci. 1997, 46, 211-236.

6. De Lamballerie-Anton, M.; Taylor, R.G.; Culioli, J. High pressure processing of meat. In Meat Processing: Improving Quality; Kerry, J., Ledward, D., Eds.; CRC Press: Cambridge, UK, 2002.

7. Macfarlane, J.J. Pressure-induced solubilization of meat proteins in saline solution. J. Food Sci. 1974, 39, 542-547.

8. Macfarlane, J.J.; McKenzie, I.J. Pressure-induced solubilization of myofibrillar proteins. J. Food Sci. 1976, 39, 1442-1446.

9. Suzuki, A.; Suzuki, N.; Ikeuchi, Y.; Saito, M. Effects of high pressure treatment on the ultrastructure and solubilization of isolated myofibrils. Agr. Bio. Chem. 1991, 55, 2467-2473.

10. Mcarthur, A.J.; Wilding, P. High pressure effects on myofibrillar proteins. In High Pressure Bioscience and Biotechnology; Hayashi, R., Balny, C., Eds.; Elsevier: Amsterdam, The Netherlands, 2002; p. 323.

11. Yamamoto, K.; Yoshida, T.; Iwasaki, T. Hydrostatic pressure-induced solubilization and gelation of chicken myofibrils. In Trends in High Pressure Bioscience and Biotechnology; Hayashi, R., Ed.; Elsevier Science B.V.: Amsterdam, The Netherlands, 2002; pp. 461-468.

12. June, S.; Lamballerie-Anton, M.D.; Ghoul, M. Modification of ultrastructure and myofibrillar proteins of post-rigor beef treated by high pressure. Lebensm. Wiss. Technol. 2000, 33, 313-319.

13. Macfarlane, J.J.; Morton, D.J. Effects of pressure treatment on the ultrastructure of striated muscle. Meat Sci. 1978, 2, 281-288.

14. Sikes, A.; Tornberg, E.; Tume, R. A proposed mechanism of tenderising post-rigor beef using high pressure-heat treatment. Meat Sci. 2010, 84, 390-399.

15. Ma, H.J.; Ledward, D.A.; Zamri, A.I.; Frazier, R.A.; Zhou, G.H. Effects of high pressure/thermal treatment on lipid oxidation in beef and chicken muscle. Food Chem. 2007, 104, 1575-1579.

16. Laemmli, U.K. Cleavage of structural proteins during the assembly of the head of bacteriophage T4. Nature 1970, 227, 680-685.

(C) 2011 by the authors; licensee MDPI, Basel, Switzerland. This article is an open access article distributed under the terms and conditions of the Creative Commons Attribution license (http://creativecommons.org/licenses/by/3.0/). 